\title{
Shortened First-Line High-Dose Chemotherapy for Patients With Poor-Prognosis Aggressive Lymphoma
}

\author{
By Christian Gisselbrecht, Eric Lepage, Thierry Molina, Bruno Quesnel, Georges Fillet, Pierre Lederlin, Bertrand Coiffier, \\ Hervé Tilly, Jean Gabarre, Francoise Guilmin, Olivier Hermine, and Félix Reyes for the Groupe \\ d'Etude des Lymphomes de l'Adulte
}

\begin{abstract}
Purpose: Randomized trial LNH93-3 was conducted on patients who had poor-prognosis aggressive lymphoma and were younger than 60 years with two to three factors of the age-adjusted International Prognostic Index to evaluate the benefit of early high-dose therapy (HDT) with autologous stem-cell transplantation (ASCT).

Patients and Methods: Patients were randomized between doxorubicin, cyclophosphamide, vindesine, bleomycin, and prednisone (ACVBP) chemotherapy followed by sequential consolidation and an experimental shortened treatment consisting of three cycles with escalated doses of cyclophosphamide, epirubicin, vindesine, bleomycin, and prednisone and collection of peripheral-blood stem cells. On day 60, HDT was administered with 1,3-bis(2-chloroethyl)-1nitrosourea, etoposide, cytarabine, and melphalan followed by ASCT.
\end{abstract}

$\mathrm{T}^{\mathrm{o}}$ IMPROVE THE cure rate for aggressive nonHodgkin's lymphoma (NHL) with adverse prognostic factors, different chemotherapy regimens have been tried over the past 20 years, but none has been proved to be clearly superior to cyclophosphamide, doxorubicin, vincristine, and prednisone (CHOP) in randomized studies. ${ }^{1}$ However, most of those regimens were designed before the use

From the Institut d'Hématologie, GELA Hôpital Saint Louis; Service d'Anatomie Pathologique, Hôtel Dieu; Service d'Hématologie, Hôpital Pitié Salpétrière; Service d'Hématologie, Hôpital Necker, Paris; Departement d'Information Hospitalier, Hôpital Henri Mondor; Service d'Hématologie, Hôpital Henri Mondor, Créteil; Centre Hospitalier Universitaire de Lille, Lille; Service d'Hématologie et Medecine interne, Centre Hospitalier Universitaire Brabois, Vandoeuvre les Nancy; Centre Hospitalier Lyon Sud, Pierre Bénite; Centre Henri Becquerel, Rouen; Service d'Hématologie, Hôpital Beaujon, Clichy, France; and Centre Hospitalier Universitaire de Liège, Domaine Universitaire de Sart Tilman, Liège, Belgium.

Submitted August 20, 2001; accepted December 14, 2001.

Supported by grants from the Ministère de la Santé (PHRC, AOM no. 95061), Assistance Publique Hôpitaux de Paris, France, and grants from Amgen-Roche, Neuilly sur Seine, France, and Asta-Medica, Merignac, France.

Address reprint requests to Christian Gisselbrecht, MD, Institut d'Hématologie, Hôpital Saint-Louis, 1 avenue Claude Vellefaux, 75475 Paris cedex 10, France; email: christian.gisselbrecht@sls.ap-hop-paris.fr.

(C) 2002 by American Society of Clinical Oncology.

0732-183X/02/2010-2472/\$20.00
Results: Eligible patients $(n=370)$ with aggressive lymphoma were analyzed. For ACVBP (181 patients) and HDT (189 patients), respective complete remission rates were $64 \%$ and $63 \%$. With a median follow-up of 60 months, 5 -year overall survival and event-free survival for ACVBP and HDT were $60 \% \pm 8 \%$ and $46 \% \pm$ $8 \%(P=.007)$ and $52 \pm 8 \%$ and $39 \pm 8 \%(P=.01)$, respectively. Survival was independently affected by age greater than $\mathbf{4 0}$ years $(P=.0003), T$-cell phenotype $(P=.009)$, bone marrow involvement $(P=.003)$, and HDT treatment group $(P=.04)$.

Conclusion: Early HDT with ASCT in high-risk patients was inferior to the ACVBP chemotherapy regimen. These results indicate that the received doseintensity before HDT was too low when compared with ACVBP and HDT and was given too early.

J Clin Oncol 20:2472-2479. () 2002 by American Society of Clinical Oncology.

of hematopoietic growth factor or high-dose chemotherapy (HDT) with autologous stem-cell transplantation (ASCT) and could not explore high-dose intensive treatment. Since the PARMA study on patients with chemosensitive relapses, ${ }^{2}$ several studies have examined HDT with ASCT as first-line treatment for aggressive NHL. ${ }^{3-10}$ Patients were selected when their responses to $\mathrm{CHOP}$ were considered insufficient; data obtained in those pilot studies suggested an advantage for HDT. Later, two randomized trials ${ }^{11-13}$ showed prolonged disease-free survival (DFS), whereas one performed in slow-responding patients to $\mathrm{CHOP}$ failed to demonstrate any benefit. ${ }^{14}$ However, three of those studies had limited numbers of patients, ${ }^{12-14}$ and for the largest one, our patient selection criteria for the LNH87-2 trial $^{11}$ was not that of a recognized and validated prognostic index, ${ }^{15}$ such as the age-adjusted International Prognostic Index (AAIPI). Subsequent analysis of the data using AAIPI demonstrated that HDT consolidation could improve overall survival (OS) and DFS only for patients who had at least two adverse prognostic factors at diagnosis and entered complete remission (CR). One of the major obstacles of this design was that the $\mathrm{CR}$ rate was only $61 \%$. In an attempt to improve the response rate and thus survival, a novel first-line regimen that incorporated HDT with early ASCT on day 60 was designed. This regimen was compared with conventional doxorubicin, cyclophosphamide, vindesine, bleomycin, and prednisone (ACVBP), ${ }^{16}$ which has shown benefit in event- 
free survival (EFS) over CHOP and methotrexate, bleomycin, cyclophosphamide, and etoposide regimens for patients with at least two adverse prognostic factors. ${ }^{17,18}$ At the first interim analysis in September 1995, the trial was stopped because of the poor experimental arm results. ${ }^{19}$ We report the final analysis of this trial with a median follow-up of 60 months.

\section{PATIENTS AND METHODS}

\section{Eligibility Criteria}

This study was conducted by the Groupe d'Etude des Lymphomes de l'Adulte (GELA) in France and Belgium. Between March 1993 and September 15, 1995, 397 consecutive patients were included in the LNH93-3 protocol. Patients had to be between 15 and 60 years of age, have newly diagnosed aggressive NHL, and present at least two of the following adverse prognostic factors as defined by the AAIPI: elevated lactate dehydrogenase (LDH) level, performance status $\geq 2$, and Ann Arbor stage $3 / 4 .{ }^{15}$ Patients who had lymphoblastic or Burkitt's lymphoma with meningeal or bone marrow involvement or had primary cerebral NHL were excluded. Other noninclusion criteria were positive serology for human immunodeficiency virus, concomitant or previous cancer (except in situ cervical carcinoma), congestive heart failure, and liver or kidney failure. The trial was approved by our institution's ethics committee, and all patients gave their written informed consent.

\section{Histologic and Immunophenotypic Analysis}

Histologic slides were reviewed by two independent pathologists from the GELA for $70 \%$ of the enrolled patients, and lymphomas were classified first according to the updated Kiel classification ${ }^{20}$ and then to the World Health Organization classification. ${ }^{21}$ Immunophenotyping studies were performed as previously described, ${ }^{22}$ and the B- or T-cell phenotype was determined for $90 \%$ of the cases. A total of 370 patients were eligible for the study, and 27 were excluded for the following reasons: incorrect histology $(\mathrm{n}=15)$, Burkitt's NHL with bone marrow involvement $(\mathrm{n}=1)$, human immunodeficiency virus seropositivity $(\mathrm{n}=1)$, and missing data $(\mathrm{n}=10)$.

\section{Staging}

The extent of the disease was evaluated by physical examination, computerized tomography (CT) scan of the chest and abdomen, CSF examination, bone marrow biopsy, and other investigational procedures depending on the clinical symptoms. Patients were staged according to the Ann Arbor classification. Performance status and toxicity were assessed according to the National Cancer Institute common toxicity criteria grading system; LDH was expressed as the maximum/normal value ratio.

\section{Treatments}

Patients were randomized between arm A and arm B. Briefly, arm A consisted of four cycles of ACVBP (doxorubicin $75 \mathrm{mg} / \mathrm{m}^{2}$ on day 1 , cyclophosphamide $1,200 \mathrm{mg} / \mathrm{m}^{2}$ on day 1 , vindesine $2 \mathrm{mg} / \mathrm{m}^{2}$ and bleomycin $10 \mathrm{mg}$ on days 1 and 5 , prednisone $60 \mathrm{mg} / \mathrm{m}^{2}$ from days 1 to 5 , and intrathecal methotrexate $15 \mathrm{mg}$ on day 2 ) at 2-week intervals followed by outpatient consolidation that lasted 4 months. ${ }^{15}$ Supportive granulocyte colony-stimulating factor (G-CSF; $5 \mu \mathrm{g} / \mathrm{kg} / \mathrm{d}$; Filgrastim, Amgen/Roche, Neuilly, France) was given on day 6 after each cycle. Patients then received consolidation at 2-week intervals, with two cycles of methotrexate $\left(3 \mathrm{~g} / \mathrm{m}^{2}\right)$ plus leucovorin rescue, four cycles of etoposide $\left(300 \mathrm{mg} / \mathrm{m}^{2}\right)$ and ifosfamide $\left(1,500 \mathrm{mg} / \mathrm{m}^{2}\right)$, and two cycles of cytarabine $\left(100 \mathrm{mg} / \mathrm{m}^{2}\right)$ subcutaneously for 4 days.

Arm B comprised a shortened intensive induction phase that consisted of one cycle of cyclophosphamide, epirubicin, vincristine, and prednisone (CEOP) (cyclophosphamide $750 \mathrm{mg} / \mathrm{m}^{2}$ on day 1, epirubicin $70 \mathrm{mg} / \mathrm{m}^{2}$ on day 1 , vincristine $1 \mathrm{mg} / \mathrm{m}^{2}$ on day 1 , and prednisone $40 \mathrm{mg} / \mathrm{m}^{2}$ on days 1 to 5 , and intrathecal methotrexate $15 \mathrm{mg}$ on day 1) and two cycles of epirubicin, cyclophosphamide, vindesine, bleomycin, and prednisone (ECVBP) on days 15 and 36 (epirubicin 120 $\mathrm{mg} / \mathrm{m}^{2}$ on day 1 , cyclophosphamide $2,000 \mathrm{mg} / \mathrm{m}^{2}$ on day 1 , vindesine $2 \mathrm{mg} / \mathrm{m}^{2}$ on days 1 and 5 , bleomycin $10 \mathrm{mg}$ on days 1 and 5 , prednisone $40 \mathrm{mg} / \mathrm{m}^{2}$ on days 1 to 5 , and intrathecal methotrexate $15 \mathrm{mg}$ ). G-CSF was given on day 6 after each ECVBP cycle. On day 60, intensified chemotherapy with 1,3-bis(2-chloroethyl)-1-nitrosourea, etoposide, cytarabine, and melphalan (BEAM) (1,3-bis(2-chloroethyl)-1-nitrosourea $300 \mathrm{mg} / \mathrm{m}^{2}$ on day -7 , etoposide $200 \mathrm{mg} / \mathrm{m}^{2}$ from day -6 to day -3 , cytarabine $200 \mathrm{mg} / \mathrm{m}^{2}$ from day -6 to day -3 , and melphalan $140 \mathrm{mg} / \mathrm{m}^{2}$ on day -2 ) was given followed by ASCT.

\section{Stem-Cell Harvesting}

Peripheral-blood stem cells (PBSC) were collected and cryopreserved after the first or second ECVBP cycle when bone marrow involvement was present at diagnosis, as previously reported, ${ }^{23}$ until analysis confirmed collection of $>2.5 \times 10^{6} \mathrm{CD} 34^{+}$cells $/ \mathrm{kg}$.

\section{Supportive Care}

All patients had an indwelling central venous catheter and were housed in a protected environment for the duration of aplasia. Broadspectrum antibiotics were given for any clinical or microbiologic infection or for a persistent undocumented fever $>38^{\circ} \mathrm{C}$ after blood had been drawn for culture.

\section{Assessment of Response and Follow-up}

CR was defined as the disappearance of all clinical evidence of disease and normalization of all laboratory values, radiographs, and biopsies from sites that had initially been abnormal. Patients with persistent $\mathrm{CT}$ abnormalities but $>75 \%$ regression of the initial tumor were considered to be in unconfirmed $\mathrm{CR}(\mathrm{CRu})$ if in $\mathrm{CR}$ on all other parameters. ${ }^{24}$ Partial response (PR) was defined as a $50 \%$ to $75 \%$ reduction of tumor volume. A lower response, progressive disease (PD), and treatment-related death were considered treatment failures. Patients whose disease progressed at any time were withdrawn from the study and given another treatment at the discretion of the treating physician. Responses were evaluated by repeating the staging procedure 1 month after completion of each treatment arm. In addition, responses in the main disease sites were assessed after ACVBP and just before HDT to detect PD. Follow-up procedures included physical examination every 3 months for the first 2 years, then every 6 months for 2 years, then annually. Thoracic and abdominal CT scans were performed every 6 months during the first 2 years, then at the discretion of the treating physician.

\section{Statistical Analyses}

For this prospective, randomized study, randomization was stratified according to the participating centers for the treatment arm and was generated by the GELA coordinating center after confirmation of the patient's eligibility. Case report forms were sent by participating centers and keyed in twice for verification. Outliers and erroneous values were checked routinely. The main objective of the trial was to 
obtain a $10 \%$ difference in EFS at 2 years. With a risk $\alpha=0.05$ and a risk $\beta=0.1$ based on the assumption of $40 \%$ 2-year EFS in the ACVBP versus $50 \%$ in the experimental arm, this design required the randomization of 700 eligible patients over 5 years. Secondary end points were response rate after completion of each treatment arm and OS. After 300 patients had been enrolled and followed for at least 6 months, the Data and Safety Monitoring Committee undertook an interim analysis, which was completed in July $1995 .{ }^{18}$ Results indicated that EFS was significantly lower in the experimental arm. The committee recommended that the study be stopped on September 15, 1995 , by which time 397 patients had been randomized and were followed to assess survival and relapses. The revised risk $\beta$ of the study with 400 patients is 0.5 .

\section{Statistical Methods}

Patient characteristics and CR rates were compared using $\chi^{2}$ and Fisher's exact tests. EFS was measured from the date of randomization to disease progression, relapse, or death from any cause or from the stopping date, which, for this analysis was, July 1, 1999. DFS was measured from the first date of remission to either relapse or death from any cause. OS was measured from the date of randomization to the date of death from any cause. Data were censored at the date of the last follow-up evaluation when the stopping date was not reached. In an intent-to-treat analysis, survival was estimated using the Kaplan-Meier method $^{25}$ and compared with the log-rank test. ${ }^{26}$ Differences were considered significant when the two-sided $P$ value was less than .05 . Estimated hazard rate of mortality was calculated. ${ }^{27}$ Multivariate analyses were performed using the Cox model for survival data and logistic regression for categorical data, ${ }^{28}$ with SAS software (v.8. SAS Institute, Cary, NC). Treatment $\times$ risk factor interactions were also included in the model.

\section{RESULTS}

\section{Patient Characteristics and Response to Treatment}

Among the 370 eligible patients (median age, 46 years; range, 60 to 15 years), 181 were randomized to receive ACVBP and 189 were randomized to receive HDT with ASCT. Their main characteristics were similar (Table 1), differing significantly only for the higher percentage of arm-B patients with extranodal site $\geq 2(P=.0004)$. Responses could be evaluated in 174 patients in arm A and 187 patients in arm B. CR + CRu rates were $64 \%$ and $63 \%$ for arms A and B, respectively. During treatment, $19 \%$ of patients in arm A and $16 \%$ of patients in arm B progressed, and, respectively, $8 \%$ and $6 \%$ died (NS). HDT with ASCT was given to 139 patients $(74 \%)$. The main reasons for not receiving intensification were disease progression $(n=24)$, refusal $(\mathrm{n}=3)$, severe toxicity during induction $(\mathrm{n}=9)$, early death $(n=8)$, and miscellaneous $(n=6)$. According to univariate analysis, adverse factors that significantly affected response rates were age $>40$ years $(P=.04)$, T-cell phenotype $(P=.005)$, B symptoms $(P=.02)$, extranodal localizations $\geq 2(P=.0005), \beta 2$ microglobulin $(P=.0001)$, bone marrow involvement $(P=.003)$, and AAIPI $3(P=.05)$.
Table 1. Initial Characteristics of the Patients According to the Treatment Group: ACVBP Versus HDT With ASCT

\begin{tabular}{|c|c|c|c|c|}
\hline Characteristic & $\begin{array}{l}\text { All Patients } \\
\begin{array}{c}(\mathrm{N}=370) \\
\text { (n) }\end{array}\end{array}$ & $\begin{array}{c}\text { ACVBP } \\
(\mathrm{n}=181) \\
(\%)\end{array}$ & $\begin{array}{c}\text { HDT }+ \text { ASCT } \\
(\mathrm{n}=189) \\
(\%)\end{array}$ & $P$ \\
\hline Median age, years & 46 & 46 & 46 & \\
\hline \multicolumn{5}{|l|}{ Age, $\mathrm{n}$} \\
\hline$\leq 40$ years & 130 & 68 & 62 & .3 \\
\hline$>40$ years & 240 & 113 & 127 & \\
\hline \multicolumn{5}{|l|}{ Sex, no. } \\
\hline Male & 220 & 105 & 116 & .5 \\
\hline Female & 150 & 76 & 73 & \\
\hline \multicolumn{5}{|l|}{ Histology } \\
\hline Diffuse large-B cell & 227 & 62.5 & 60 & .07 \\
\hline Non-anaplastic PTCL & 55 & 10.5 & 19 & \\
\hline Anaplastic PTCL & 29 & 10.5 & 5 & \\
\hline Lymphoblastic & 12 & 4 & 3 & \\
\hline Burkitt's & 7 & 0.5 & 3 & \\
\hline Diffuse aggressive, unclassifiable & 40 & 12 & 9.5 & \\
\hline \multicolumn{5}{|l|}{ Cell phenotype } \\
\hline B & 257 & 79 & 75 & .3 \\
\hline$T$ & 76 & 20 & 24 & \\
\hline \multicolumn{5}{|l|}{ B symptoms } \\
\hline Absent & 111 & 33 & 27 & .2 \\
\hline Present & 258 & 67 & 73 & \\
\hline \multicolumn{5}{|l|}{ Performance status grade } \\
\hline $0-1$ & 197 & 52 & 55 & .4 \\
\hline$>1$ & 169 & 47 & 45 & \\
\hline \multicolumn{5}{|l|}{ Ann Arbor stage } \\
\hline $\mathrm{I-II}$ & 21 & 5 & 6 & .5 \\
\hline III-IV & 349 & 95 & 94 & \\
\hline \multicolumn{5}{|l|}{ No. of extranodal sites } \\
\hline $0-1$ & 136 & 46 & 28 & .0004 \\
\hline$\geq 2$ & 234 & 54 & 72 & \\
\hline \multicolumn{5}{|l|}{ Bone marrow involvement } \\
\hline Absent & 255 & 74 & 68 & .2 \\
\hline Present & 104 & 26 & 32 & \\
\hline \multicolumn{5}{|l|}{ Tumor bulk } \\
\hline$<10 \mathrm{~cm}$ & 193 & 52 & 56 & .4 \\
\hline$\geq 10 \mathrm{~cm}$ & 165 & 48 & 44 & \\
\hline Meningeal involvement & 13 & 3.5 & 4 & .8 \\
\hline \multicolumn{5}{|l|}{ Hemoglobin } \\
\hline$\geq 10 \mathrm{~g} / \mathrm{dL}$ & 290 & 80 & 78 & .8 \\
\hline$<10 \mathrm{~g} / \mathrm{dL}$ & 78 & 20 & 22 & \\
\hline \multicolumn{5}{|l|}{ Serum LDH level } \\
\hline$<$ normal & 26 & 9 & 6 & \\
\hline$\geq$ normal & 342 & 91 & 94 & .17 \\
\hline \multicolumn{5}{|l|}{ Serum albumin level } \\
\hline$\geq 35 \mathrm{~g} / \mathrm{L}$ & 193 & 44 & 55 & \\
\hline$<35 \mathrm{~g} / \mathrm{L}$ & 157 & 56 & 45 & .8 \\
\hline \multicolumn{5}{|l|}{$\beta 2$ microglobulin } \\
\hline$<3$ & 162 & 55 & 54 & .7 \\
\hline$\geq 3$ & 135 & 45 & 46 & \\
\hline \multicolumn{5}{|l|}{ No. of AAIPI factors } \\
\hline 1 & 7 & 2.8 & 1 & \\
\hline 2 & 231 & 61.5 & 65 & .4 \\
\hline 3 & 127 & 35.5 & 34 & \\
\hline
\end{tabular}

NOTE. Except for Age and Sex rows, all values in the ACVBP and HDT + ASCT columns are percentages.

Abbreviation: PTCL, peripheral T-cell lymphoma. 


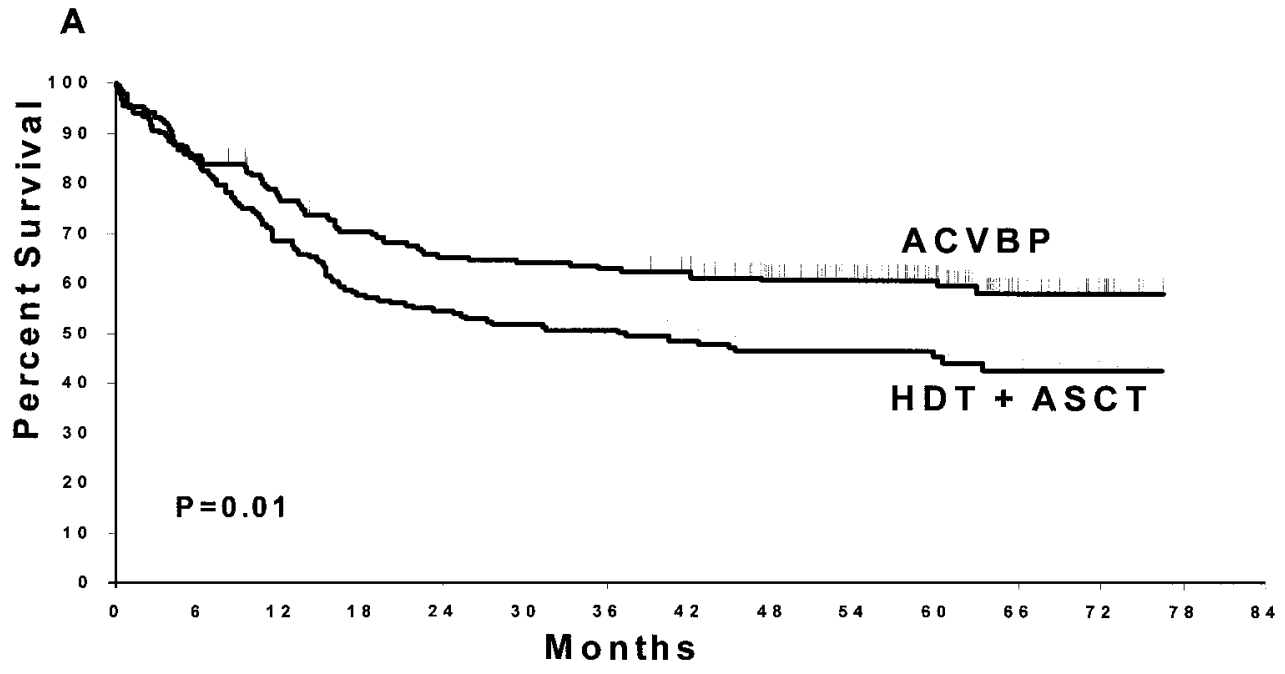

$\mathbf{B}$

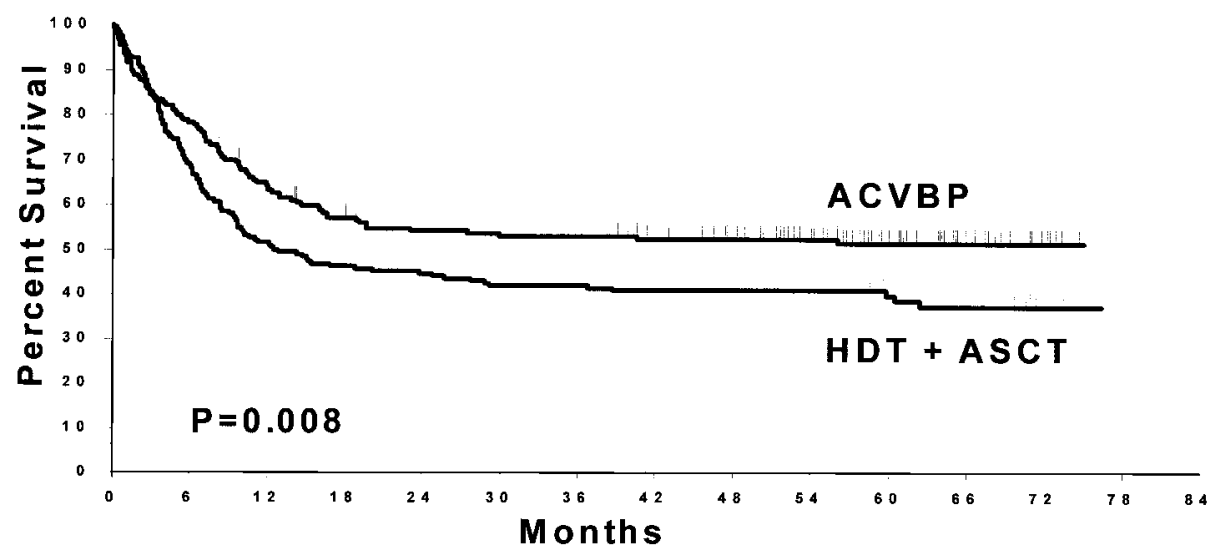

Fig 1. OS (A) and EFS (B) of the 181 patients who were treated with ACVBP and the 189 patients who received early HDT and ASCT.

\section{Dose-Intensity}

The median received dose-intensity, calculated for the first 8 weeks of the ACVBP arm, were $35 \mathrm{mg} / \mathrm{m}^{2} / \mathrm{wk}$ for doxorubicin and $565 \mathrm{mg} / \mathrm{m}^{2} / \mathrm{wk}$ for cyclophosphamide and represents $94 \%$ of the planned dose-intensity, respectively, $37.5 \mathrm{mg} / \mathrm{m}^{2} / \mathrm{wk}$ and $600 \mathrm{mg} / \mathrm{m}^{2} / \mathrm{wk}$. For arm B, the median received dose-intensities calculated from CEOP to ASCT were $31 \mathrm{mg} / \mathrm{m}^{2} / \mathrm{wk}$ for epirubicin and $475 \mathrm{mg} / \mathrm{m}^{2} / \mathrm{wk}$ for cyclophosphamide, with a median CEOP-BEAM interval of 72 days (range, 53 to 191 days), meaning a 20\% lowerthan-planned dose-intensity.

\section{Toxicity}

During the first cycle of ACVBP or CEOP, grade 4 hematotoxicity for $\mathrm{WBC}$ was observed, respectively, in $82 \%$ and $50 \%$ of the cases. The respective rates of grade 3 or 4 infections were $26 \%$ and $19 \%$, with two infectionrelated deaths in arm B and one in arm A. For the other cycles, the same percentages of grade 3 to 4 hematotoxicity $(80 \%)$ and grade 3 to 4 infections $(18 \%)$ were observed in both arms.

Leukaphereses were performed after the first $(57 \%)$ or second (38\%) ECVBP cycle with a median of two leukaphereses. The median numbers of GM-CFU and CD34+ cells were, respectively, $37.8 \times 10^{4} / \mathrm{kg}$ (range, 2 to $730 \times$ $10^{4} / \mathrm{kg}$ ) and $12.4 \times 10^{6} / \mathrm{kg}$ (range, 1.8 to $111 \times 10^{6} / \mathrm{kg}$ ). After BEAM, all patients recovered neutrophil counts $>0.5$ $\times 10^{9} / \mathrm{L}$ after a mean of 12.4 days (range, 7 to 41 days) and a platelets count $>50 \times 109 / \mathrm{L}$ after a mean of 15.6 days (range, 9 to 141 days). Severe grade $3 / 4$ infections were observed in $10 \%$ of the patients and grade $3 / 4$ mucositis in $14 \%$. The two transplantation-related deaths occurred in 
Table 2. Five-Year EFS and OS of Patients Treated in the LNH93-3 Protocol: Chemotherapy ACVBP Versus HDT With ASCT

\begin{tabular}{|c|c|c|c|c|c|}
\hline Parameter & $\begin{array}{l}\text { Total No. } \\
\text { of Patients }\end{array}$ & EFS (\%) & $P$ & OS (\%) & $P$ \\
\hline No. & 370 & 45 & & 52 & \\
\hline ACVBP & 181 & 51 & .01 & 60 & .007 \\
\hline HDT & 189 & 39 & & 46 & \\
\hline \multicolumn{6}{|l|}{ Age } \\
\hline$<40$ years & 131 & 59 & .001 & 66 & .0001 \\
\hline$\geq 40$ years & 239 & 37 & & 44 & \\
\hline \multicolumn{6}{|l|}{ LDH } \\
\hline$\geq$ Normal & 341 & 44 & & 51 & \\
\hline$<$ Normal & 26 & 61 & .1 & 65 & .1 \\
\hline \multicolumn{6}{|l|}{ Performance status } \\
\hline $0-1$ & 196 & 43 & .9 & 51 & .9 \\
\hline$>1$ & 169 & 48 & & 53 & \\
\hline \multicolumn{6}{|l|}{ Stage } \\
\hline I-II & 21 & 61 & .1 & 66 & .2 \\
\hline II-IV & 348 & 44 & & 51 & \\
\hline \multicolumn{6}{|l|}{ Extranodal sites } \\
\hline $0-1$ & 135 & 51 & .04 & 59 & .03 \\
\hline$>1$ & 234 & 42 & & 48 & \\
\hline \multicolumn{6}{|c|}{ Bone marrow involvement } \\
\hline Negative & 254 & 52 & & 58 & \\
\hline Positive & 104 & 26 & .0001 & 33 & .0001 \\
\hline \multicolumn{6}{|l|}{ Phenotype } \\
\hline ACVBP (B cell) & 126 & 53 & .09 & 61 & .03 \\
\hline HDT (B cell) & 130 & 43 & & 47 & \\
\hline ACVBP (T cell) & 33 & 30 & .4 & 39 & .5 \\
\hline HDT (T cell) & 43 & 20 & & 32 & \\
\hline \multicolumn{6}{|c|}{ Bone marrow involvement positive } \\
\hline ACVBP & 45 & 35 & .07 & 40 & .1 \\
\hline HDT & 59 & 20 & & 29 & \\
\hline \multicolumn{6}{|l|}{ Extranodal site $>1$} \\
\hline ACVBP & 98 & 51 & .05 & 57 & .05 \\
\hline HDT & 136 & 36 & & 42 & \\
\hline \multicolumn{6}{|l|}{$\mathrm{LDH}>$ normal } \\
\hline ACVBP & 162 & 51 & .02 & 59 & .009 \\
\hline HDT & 179 & 39 & & 45 & \\
\hline \multicolumn{6}{|l|}{ AAIPI $>2$} \\
\hline ACVBP & 63 & 47 & .5 & 52 & .9 \\
\hline HDT & 64 & 40 & & 48 & \\
\hline
\end{tabular}

patients in CR. The median duration of hospitalization was 24 days (range, 17 to 44 days).

\section{Survival}

After a median follow-up of 5 years, 176 patients had died. For the entire cohort, estimated OS, EFS, and DFS probabilities were $52 \%, 45 \%$, and $67 \%$, respectively. According to intent-to-treat analysis, arms $\mathrm{A}$ and $\mathrm{B}$ differed significantly for 5-year OS $(60 \% \pm 8 \% v 46 \% \pm 8 \% ; P=$ .007 ; Fig 1) and 5-year EFS $(51 \% \pm 8 \%$ v $39 \% \pm 8 \% ; P=$ $.01)$ and DFS $(76 \% \vee 58 \% ; P=.004)$. These differences remained when the analysis was restricted to B-cell lymphoma patients who achieved CR (Table 2), with respective DFS for arm $\mathrm{A}$ and $\mathrm{B}$ of $76 \%$ and $61 \%(P=.04)$. In a multivariate analysis, OS was independently affected by age < 40 years $(P=.0003)$, bone marrow involvement $(P=.003)$, T-cell phenotype $(P=.009)$, and treatment arm $(P=.04)$. No risk factor $\times$ treatment arm interaction was found. For the 139 patients who received HDT with ASCT, the OS rate was 56\% at 5 years, and none of the factors described above as affecting survival was retained in the multivariate analysis.

\section{Relapses}

Seventy-three patients relapsed after remission. The estimated hazards rate of mortality during the study period was higher for arm B as a result of relapses (Fig 2). Patients who relapsed and progressed received different salvage chemotherapy regimens: for arms $\mathrm{A}$ and $\mathrm{B}$, allogeneic transplan- 


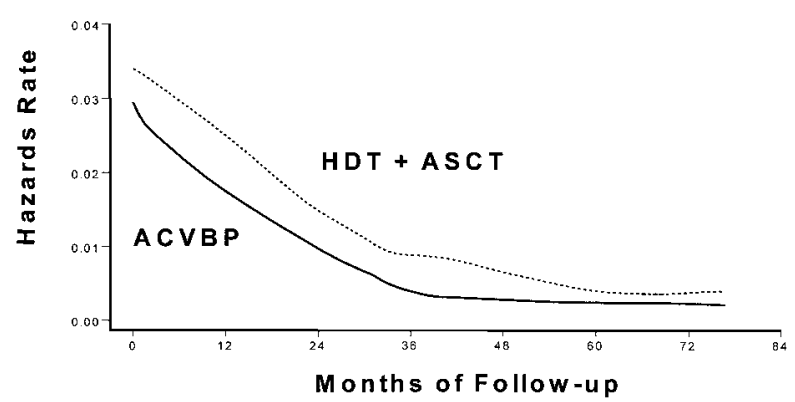

Fig 2. Estimated hazards rates mortality for patients who were treated with ACVBP and those who received early HDT and ASCT.

tations for two and six patients, respectively, and HDT with ASCT for 25 and 17 patients, respectively. The OS rate for this subpopulation was lower for arm B $(13 \% \pm 0.04 \%)$ than for arm A $(21 \% \pm 0.1 \% ; P=.01)$ at 5 years (Fig 3$)$. For relapsing patients only, the respective survival rates were $33 \%$ and $13 \%(P=.0006)$.

\section{DISCUSSION}

The AAIPI is now accepted as being able to identify patients who have aggressive lymphoma with different likelihoods of being cured with standard treatment. Fewer than $50 \%$ of the patients in the high/intermediate- or high-risk group are cured; consequently, patients younger than 60 years are appropriate candidates for experimental therapy. ${ }^{3}$ These features describe the patients with more than one AAIPI factor included in this trial. They differed only from those enrolled onto our previous study that tested HDT after $\mathrm{CR}^{11}$ by their higher percentages of $\mathrm{T}$-cell lymphomas and with more than two extranodal sites. In the LNH87-2, only 61\% (277 of 451) of these higher risk patients achieved CR after induction treatment. ${ }^{11}$ The goal of the new shortened regimen was to introduce HDT with BEAM earlier to improve the first CR rate. This result was not achieved, and the response rates were similar in the two arms. This lack of improvement may reflect inadequate dose intensity for the experimental arm during the first 8 weeks. It can be argued that dose equivalence between doxorubicin and epirubicin has not been clearly established, but considering the cumulative dose inducing cardiac toxicity, it might be closer to 1.8 than 1 for epirubicin. ${ }^{29}$ Consequently, arm $\mathrm{B}$ received less anthracycline and this situation was further aggravated by the $20 \%$ reduction of the received median dose intensity as a result of a 12-day delay in performing ASCT, mainly for logistic reasons. Moreover, the lower CEOP dosage in the first cycle did not result in a significant reduction of grade 3 to 4 infections. Intensification of the initial induction phase was first proposed by the Milan group in a different scheme with dose-escalated agents followed, on day 60, by HDT with melphalan mitoxantrone and PBSC. ${ }^{13}$ In 98 randomized patients with B large-cell lymphoma without bone marrow involvement, their sequential HDT regimen was superior to conventional chemotherapy in terms of CR rate and 7-year EFS of $76 \%$ and $49 \%$, respectively $(P=.004)$.

We achieved a $63 \% \mathrm{CR}$ rate in arm $\mathrm{B}$, and one could expect a similar outcome. Surprising is that more relapses occurred in all situations, B-cell or T-cell lymphoma, with or without bone marrow involvement.

Multivariate analysis identified that age $>40$ years, T-cell phenotype, bone marrow involvement, and arm B were independent parameters influencing survival. Several hypotheses were advanced to explain these results. First, there was a potential role of stem-cell contamination in patients with bone marrow involvement. Monitoring of residual disease in aggressive lymphoma is not yet optimal

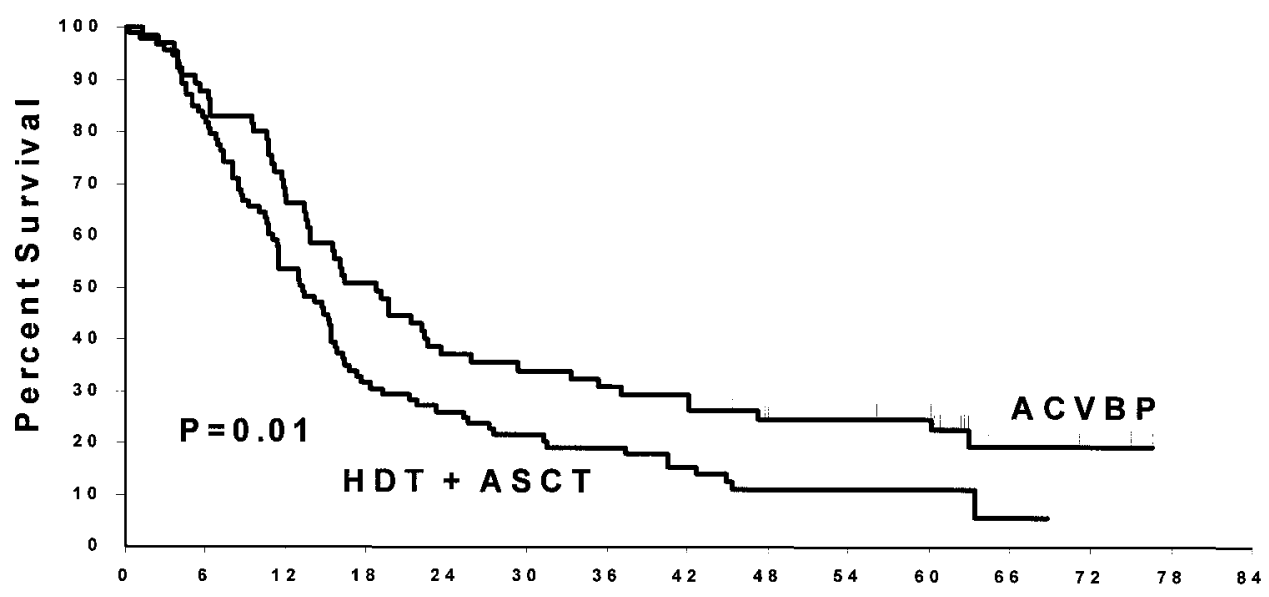

Fig 3. OS of patients who experienced disease progression or relapse and had been receiving ACVBP or early HDT and ASCT. 
and was not prospectively scheduled. In this multicenter study, specimens were not available for retrospective analysis. However, a recent quantitative study of PBSC from patients with diffuse large-cell lymphoma showed that one half strongly mobilized a significant number of malignant cells, which could be responsible for relapses. ${ }^{30}$ It should be pointed out that the difference between our two arms cannot be explained only by this hypothesis, as a difference was also noted in patients without bone marrow involvement at diagnosis. Moreover, the multivariate analysis performed only on arm B failed to identify any significant independent parameter. Second, relapsing patients in arm B could not be saved easily by introducing HDT with ASCT. In fact, very few $(<15 \%)$ patients after relapses from either arm were saved with transplantation as observed in previous studies on high-risk patients and attributed to resistance to salvage chemotherapy. ${ }^{11,31}$ Third, the results obtained with ACVBP were better than expected. With a $60 \% 5$-year probability of OS, the results obtained in LNH93 arm A compared favorably with all of our previous reports with this regimen. ${ }^{32}$ Perhaps G-CSF played a major role, as the median received ACVBP dose-intensity was $94 \%$ with the use of G-CSF in contrast to the $56 \%$ for patients who had received, $80 \%$ of the dose-intensity planned in the LNH87-2 study before the availability of G-CSF. ${ }^{33}$ However, a randomized study of patients who were treated with ACVBP with or without G-CSF failed to demonstrate any EFS advantage ${ }^{34}$ between the two arms. Last, the treatment duration seems to play a crucial role as in other hematologic diseases in which consolidation contributes to preventing relapses, and the intermittent use of sequential chemotherapy in the control arm over a longer period of time might result in an effective fractional cell kill in the drug-sensitive patients. In the recent report on the European Organization for Research and Treatment of Cancer randomized study comparing standard chemotherapy with or without HDT, there was no difference between the two arms, ${ }^{35}$ but only 60 patients with two AAIPI factors were randomized. The German HighGrade Lymphoma Study Group reported on 312 patients who had elevated LDH and stage 2 to 4 disease and received six cycles of cyclophosphamide, doxorubicin, vincristine, etoposide, and prednisone followed by radiation or a shortened protocol with three cycles of cyclophosphamide, doxorubicin, vincristine, etoposide, and prednisone followed by ASCT and radiation. ${ }^{36}$ After 30 months of follow-up, EFS and OS for patients with high/intermediateor high-risk factors did not differ. The results obtained in the LNH87-2 study led us to conclude that HDT would benefit only patients who achieved a good response before full standard induction treatment and that it should not be performed too early during the course of treatment. These conclusions resemble to the recognition of the roles of intensive consolidation and treatment duration after remission in other hematologic malignancies, eg, acute leukemia. Nevertheless, improving the $\mathrm{CR}$ rate remains the major goal for these high-risk patients. Incorporating new agents, such as anti$\mathrm{CD} 20,{ }^{37}$ might be the easiest way to improve the results obtained with chemotherapy ${ }^{1,17}$ followed or not by consolidation with HDT and are presently under investigation. For avoiding exposing patients unnecessarily to experimental approaches, close monitoring and respect of planned interim analyses of randomized trials are mandatory. However, owing to the need for sufficient follow-up before analyzing data, a sequential test approach might be more appropriate to speed up decision making but requires timely communication between clinical investigators and the experienced statisticians.

\section{ACKNOWLEDGMENT}

We thank N. Mounier for statistical advices, N. Nio for data management, J.B Golfier and I. Gaillard for data monitoring, C. Barli-Druon for secretarial assistance, and J. Jacobson for reviewing the English.

\section{APPENDIX}

The appendix listing participating investigators is available online at www.jco.org.

\section{REFERENCES}

1. Fisher RI, Gaynor ER, Dahlberg S, et al: Comparison of a standard regimen (CHOP) with three intensive chemotherapy regimens for advanced non-Hodgkin's lymphoma. N Engl J Med 328:1002-1006, 1993

2. Philip T, Guglielmi C, Hagenbeek A, et al: Autologous bone marrow transplantation as compared with salvage chemotherapy in relapses of chemotherapy-sensitive non-Hodgkin's lymphoma. N Engl J Med 333:1540-1545, 1995

3. Shipp MA, Abeloff MD, Antman KH, et al: International Consensus Conference on High-Dose Therapy with Hematopoietic Stem-
Cell Transplantation in Aggressive Non-Hodgkin's Lymphomas: Report of the jury. J Clin Oncol 17:3128-3135, 1999

4. Gulati SC, Shank B, Black P, et al: Autologous bone marrow transplantation for patients with poor-prognosis lymphoma. J Clin Oncol 6:1303-1313, 1988

5. Nademanee A, Schmidt GM, O'Donnel MR, et al: High-dose chemotherapy followed by autologous bone marrow transplantation as consolidation therapy during first complete remission in adult patients with poor-risk aggressive lymphoma: A pilot study. Blood 80:11301134,1992 
6. Freedman AS, Takvorian T, Neuberg D, et al: Autologous bone marrow transplantation in poor-prognosis intermediate-grade and highgrade B-cell non-Hodgkin's lymphoma in first remission: A pilot study. J Clin Oncol 11:931-936, 1993

7. Sierra J, Conde E, Montserrat E: Autologous bone marrow transplantation for non-Hodgkin's lymphoma in first remission. Blood 81:1968, 1993 (letter)

8. Pettengel R, Radford JA, Morgenstern GR, et al: Survival benefit from high-dose therapy with autologous blood progenitor cell transplantation in poor-prognosis non-Hodgkin's lymphoma. J Clin Oncol 14:586-592, 1996

9. Cortelazzo S, Rossi A, Bellavita P, et al: Clinical outcome after autologous transplantation in non-Hodgkin's lymphoma patients with high international prognostic index (IPI). Ann Oncol 10:427-432, 1999

10. Vitolo U, Cortellazzo S, Liberati AM, et al: Intensified and high-dose chemotherapy with granulocyte colony-stimulating factor and autologous stem-cell transplantation support as first-line therapy in high risk diffuse large-cell lymphoma. J Clin Oncol 15:491-498, 1997

11. Haioun C, Lepage E, Gisselbrecht C, et al: Survival benefit of high dose therapy in poor risk aggressive non-Hodgkin's lymphoma: Final analysis of the prospective LNH87-2 protocol-A Groupe d'Etude des Lymphomes de l'Adulte study. J Clin Oncol 18:30253030,2000

12. Santini G, Salvagno L, Leoni $P$, et al: VACOP-B versus VACOP-B plus autologous bone marrow transplantation for advanced diffuse non-Hodgkin's lymphoma: Results of a prospective randomized trial by the Non-Hodgkin's Lymphoma Cooperative Study Group. J Clin Oncol 16:2796-2802, 1998

13. Gianni AM, Bregni M, Siena S, et al: High-dose chemotherapy and autologous bone marrow transplantation compared with MACOP-B in aggressive B-cell lymphoma. N Engl J Med 336:1290-1297, 1997

14. Verdonck LF, Van Putten WLJ, Hagenbeek A, et al: Comparison of CHOP chemotherapy with autologous bone marrow transplantation for slowly responding patients with aggressive non-Hodgkin's lymphoma. N Engl J Med 332:1045-1051, 1995

15. The International Non-Hodgkin's Lymphoma Prognostic Factors Project: A predictive model for aggressive non-Hodgkin's lymphoma. N Engl J Med 329:987-994, 1993

16. Coiffier B, Gisselbrecht C, Herbrecht R, et al: LNH-84 regimen: A multicenter study of intensive chemotherapy in 737 patients with aggressive malignant lymphoma. J Clin Oncol 7:1018-1026, 1989

17. Tilly H, Mounier N, Lederlin P, et al: Randomized comparison of ACVBP and m-BACOD in the treatment of patients with low-risk aggressive lymphoma: The LNH87-1 study. J Clin Oncol 18:13091315,2000

18. Tilly H, Lepage E, Coiffier B, et al: A randomized comparison of ACVBP and CHOP in the treatment of advanced aggressive non-Hodgkin's lymphoma: The LNH93-5 study. Blood 96:11, 2000 (abstract 3596)

19. Gisselbrecht C, Lepage E, Morel P, et al: Intensified phase including autologous peripheral stem cell transplantation does not improve response rate and survival in lymphoma with at least 2 adverse prognostic factors when compared to ACVB regimen. (ASH, 38th annual meeting. Orlando, FL, December 6-10). Blood 88:10, 1996 (abstract 470)

20. Stansfeld AG, Diebold J, Noel H, et al: Updated Kiel classification for lymphomas. Lancet 1:292-293, 1988 (letter)
21. Harris NL, Jaffe ES, Diebold J, et al: World Health Organization classification of neoplastic diseases of the hematopoietic and lymphoid tissues: Report of the Clinical Advisory Committee meeting-Airlie House. Virginia, November 1997. J Clin Oncol 17:3835-3849, 1999

22. Gisselbrecht C, Gaulard P, Lepage E, et al: Prognostic significance of T-cell phenotype in aggressive non-Hodgkin's lymphomas. Blood 92:76-82, 1998

23. Langouët AM, Brice P, Simon D, et al: Factors affecting hematopoietic recovery after autologous peripheral blood progenitorcell transplantation in aggressive non-Hodgkin's lymphoma: A prospective study of 123 patients. Hematol J 2:81-86, 2001

24. Cheson BD, Horning SJ, Coiffier B, et al: Report of an international workshop to standardize response criteria for nonHodgkin's lymphoma. J Clin Oncol 17:1244-1253, 1999

25. Kaplan EL, Meier P: Non parametric estimation from incomplete observations. J Am Stat Assoc 53:457-481, 1958

26. Mantel N: Evaluation of survival data and two new rank order statistics arising in its consideration. Cancer Chemother Rep 50:163170,1966

27. Hess KR, Serachitopol DM, Brown BW: Hazard function estimators: A simulation study. Stat Med 18:3075-3088, 1999

28. Cox DR: Regression models and life tables. J R Stat Soc (B) 34:187-202, 1972

29. Launchbury AP, Habboubit N: Epirubicin and doxorubicin: A comparison of their characteristics, therapeutic activity and toxicity. Cancer Treat Rev 19:197-228, 1993

30. Jacquy C, Sorée A, Lambert F, et al: A quantitative study of peripheral blood stem cell contamination in diffuse large-cell nonHodgkin's lymphoma: One-half of patients significantly mobilize malignant cells. Br J Haematol 110:631-637, 2000

31. Mounier N, Haioun C, Cole BF, et al: Quality of life-adjusted survival analysis of high-dose therapy with autologous bone marrow transplantation versus sequential chemotherapy for patients with aggressive lymphoma in first complete remission. Blood 95:3687-3692, 2000

32. Haioun C, Lepage E, Gisselbrecht C, et al: Benefit of autologous bone marrow transplantation over sequential chemotherapy in poor risk aggressive non Hodgkin's lymphoma: Updated results of the prospective study LNH87-2. Groupe d'Etude des Lymphomes de l'Adulte. J Clin Oncol 15:1131-1137, 1997

33. Lepage E, Gisselbrecht C, Haioun C, et al: Prognostic significance of received relative dose intensity in non-Hodgkin's lymphoma patients: Application to the LNH-87 protocol. Ann Oncol 4:651-656, 1993

34. Gisselbrecht C, Haioun C, Lepage E, et al: Placebo controlled phase III trial of lenograstim (glycosylated recombinant human G-CSF) in aggressive non-Hodgkin's lymphoma. Leuk Lymph 25:289-300, 1997

35. Kluin-Nelemans HC, Zagonel V, Anastasopoulou A, et al: Standard chemotherapy with or without high-dose chemotherapy for aggressive non-Hodgkin's lymphoma: Randomized phase III EORTC study. J Natl Cancer Inst 93:22-30, 2001

36. Kaiser U, Uebelacker I, Birkmann J, et al: High dose therapy with autologous stem cell transplantation in aggressive NHL: Results of a randomized multicenter study. Blood 94:671, 1999 (abstract 2716)

37. Coiffier B, Lepage E, Brière $\mathrm{J}$, et al: CHOP plus rituximab with CHOP chemotherapy in elderly patients with diffuse large B-cell lymphoma: A Groupe d'Etude des Lymphomes de l'Adulte study. N Engl J Med 346:235-242, 2002 